\title{
Laryngitis, Tracheitis, Epiglottitis, and Bronchiolitis
}

\section{Sore Throat, Change in Voice, Fever}

or

a Wheezing Infant in Respiratory Distress

Debra Tristram

7.1 Laryngitis, Laryngotracheitis, and

Laryngotracheobronchitis - 76

7.2 Definitions - 76

7.3 Laryngitis -76

7.4 Croup -78

7.5 Bacterial Tracheitis -80

7.6 Epiglottitis -80

7.7 Exercises -81

7.8 Summary -81

7.9 Bronchiolitis -81

7.10 Definitions -82

7.11 Summary -84

References - 84 


\section{Learning Objectives}

- Explain the etiology, epidemiology, and clinical presentation of middle and lower airway infection in infants and children

- Formulate a differential diagnosis for respiratory distress in infants and children

- Describe the appropriate management of middle airway disease including laryngitis, croup, tracheitis, and epiglottitis

- Understand how viral bronchiolitis is diagnosed and treated

\subsection{Laryngitis, Laryngotracheitis, and Laryngotracheobronchitis}

The larynx and adjacent trachea are very prone to viral infections. Acute, isolated laryngitis is primarily a disease seen in older children, adolescents, and adults. In young children there is generally involvement of other adjacent structures in the upper respiratory tract and the lower respiratory tree; this condition is called acute laryngotracheitis, or croup. Acute laryngotracheitis may also extend into the lower respiratory tract presenting as acute laryngotracheobronchitis (LTB). Nearly all cases of acute croup are caused by viruses. In contrast, isolated tracheitis is rare and is more likely to be caused by a bacterium than a virus.

\subsection{Definitions}

Laryngitis - Laryngitis is defined as inflammation of the larynx, typically resulting in huskiness or loss of the voice, harsh breathing, dysphonia, and/or a painful cough.

Laryngotracheitis (croup) - Laryngotracheitis (or laryngotracheobronchitis, LTB) is an acute respiratory illness that involves infection of the larynx and the tracheobronchial tree.

Tracheitis - Tracheitis is defined as an acute infection or inflammation of the trachea. Bacterial tracheitis is an acute croup-like bacterial infection of the upper airway in children, with coughing and high fever, while viral tracheitis is often part of an acute viral infection that typically involves the larynx as well as the upper and lower respiratory tract.
Epiglottitis - Epiglottitis is an acute bacterial infection of the epiglottis and surrounding supraglottic tissues. Most cases of pediatric epiglottitis were once caused by Haemophilus influenzae serotype $B$, an infection nearly eliminated from all areas of the world where $H$. influenzae serotype $B$ vaccination programs are in place. Currently, epiglottitis still occurs sporadically across all age groups with Staphylococcus aureus accounting for most disease beyond the age of 5 years.

\subsection{Laryngitis}

Acute laryngitis generally results from a viral infection that causes edema of the vocal cords, either by directly infecting the tissues or by stimulating excessive secretions that lead to inflammation. Most cases of acute laryngitis are caused by viruses (• Fig. 7.1). Adenoviruses and influenza viruses are most commonly implicated, but infection with any of the common respiratory viruses can manifest as laryngitis. Acute bacterial laryngitis is rare in the era of vaccination, but one may encounter cases of acute diphtheria in unimmunized populations, particularly with growing vaccine hesitancy in the United States and Europe. When laryngitis presents as a chronic condition, an underlying viral etiology is possible, but a noninfectious etiology is far more likely. The differential diagnosis for chronic laryngitis includes trauma, allergic or chemical inflammation, tumor infiltration, and congenital anomalies.

The main clinical feature of acute laryngitis is a change in pitch or sound of the voice with associated huskiness, hoarseness, or complete aphonia. Nonspecific features of an upper respiratory infection are commonly present including nasal congestion, sore throat, and cough. Patients may complain that it hurts to speak. Viruses that cause laryngitis can also cause croup as the infection spreads to the more distal, adjacent airway structures. A more insidious presentation of laryngitis occurs following the vertical transmission of human papillomaviruses (HPV) from mother to child. The presence of a maternal infection with a low-oncogenic-risk HPV type (most commonly HPV type 6) at the time of birth
- Fig. 7.1 This pie chart shows the percentage of laryngitis cases caused by each group of common respiratory viruses

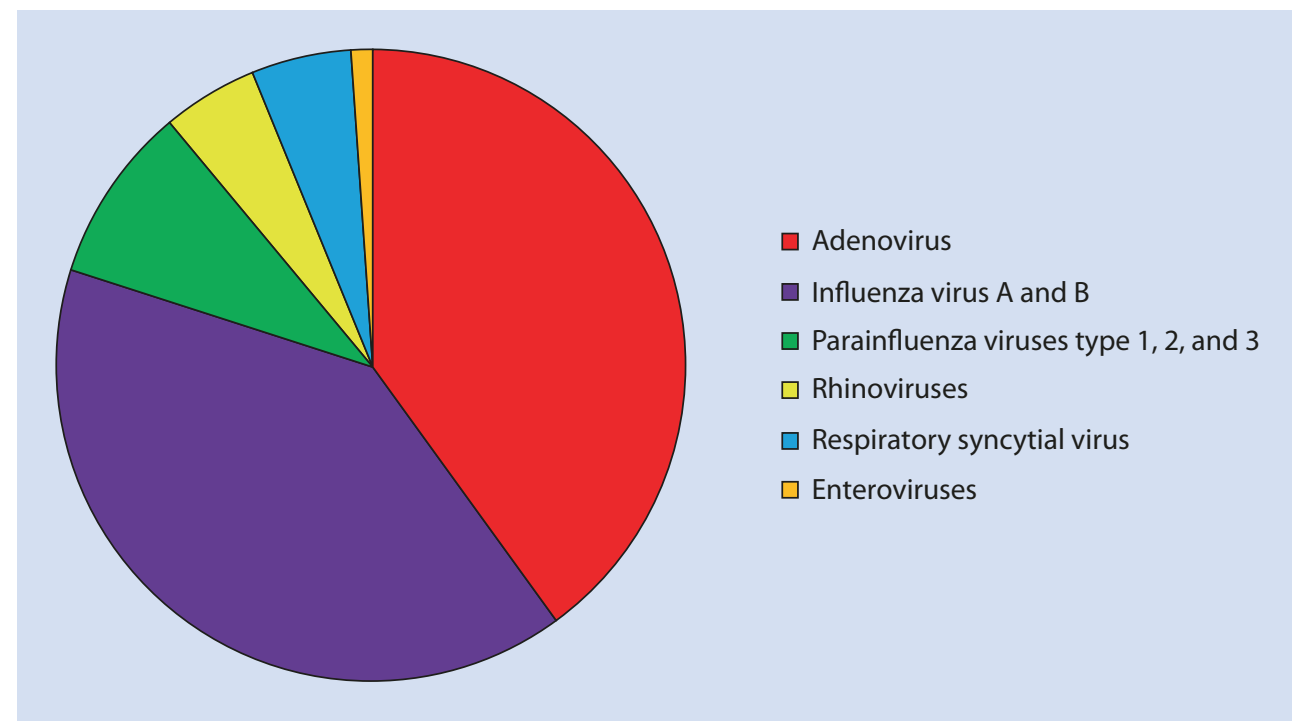


puts the newborn at risk for infection whether the mother has visible genital condylomata or not. Exposed infants may develop HPV infection in or around their vocal cords with subsequent growth of papillomas. Presenting signs and symptoms mimic viral croup, but do not completely resolve. Direct visualization using nasopharyngeal laryngoscopy is diagnostic. Surgical ablation using laser energy reduces the size of the lesions, but recurrences are expected. Recurrent respiratory papillomatosis mimics croup, and is caused by a virus, but it is a unique entity that can be very challenging to manage.

In otherwise healthy individuals, acute laryngitis is a self-limited illness lasting between 3 and 7 days. Since the vast majority of cases are due to viral infections, the use of antibiotics is not indicated. Maintenance of good hydration and resting the voice are generally sufficient therapy for acute disease. Patients should avoid "whispering" as this tends to increase trauma to vocal cords that are already irritated. Decongestant medications may be helpful if they are not too drying.

The differential diagnosis for a patient with acute vocal changes includes laryngeal edema due to trauma, particularly following toxic ingestions (e.g., lye) or inhalations, acute allergic reactions, foreign body aspiration or ingestion, and epiglottitis ( $\triangleright$ Box 7.1). High fever accompanied by a toxic appearance suggests an alternative diagnosis, such as epiglottitis or bacterial infection of the pharyngeal/parapharyngeal space. More insidious or chronic changes can be due to the presence of a congenital malformation, perinatally acquired respiratory papillomatosis, gastroesophageal reflux, allergic rhinitis, vocal cord nodules, or, rarely, malignancies of the larynx, vocal cords, or surrounding structures.

\section{Box 7.1 Differential Diagnosis of Respiratory Distress by Clinical Diagnosis}

\begin{tabular}{|c|c|c|}
\hline Clinical condition & Differential diagnosis & Helpful clues to diagnosis \\
\hline \multirow[t]{7}{*}{ Laryngitis } & Toxic ingestion (e.g., lye) & History of exposure \\
\hline & Toxic inhalation & History of exposure \\
\hline & Voice overuse (e.g., singers) & History of prolonged talking or singing \\
\hline & Acute allergic reactions & History of exposure, new food, bee sting \\
\hline & Foreign body lodged in the larynx & History of sudden onset of choking followed by laryngitis \\
\hline & Epiglottitis & Toxic appearance, high fever, drooling \\
\hline & Croup & Barky cough, fever \\
\hline \multirow[t]{6}{*}{ Croup } & Airway trauma/toxic exposures & History of exposure, smoke inhalation, other toxins \\
\hline & Angioedema & Allergic history \\
\hline & Foreign body aspiration & Sudden onset of choking or vomiting with choking \\
\hline & Epiglottitis & Toxic appearance, high fever, drooling \\
\hline & Gastroesophageal reflux & Feeding refusal, respiratory symptoms \\
\hline & Retro- or parapharyngeal abscesses & Toxic appearance, fever, difficulty swallowing, sore throat \\
\hline \multirow[t]{3}{*}{ Tracheitis } & Similar to croup differential & As above \\
\hline & \multirow[t]{2}{*}{ Diphtheria } & $\begin{array}{l}\text { History of prolonged endotracheal intubation followed } \\
\text { by respiratory distress with fever }\end{array}$ \\
\hline & & Unimmunized with or without known exposure \\
\hline \multirow[t]{6}{*}{ Bronchiolitis } & Acute exacerbation of asthma & Personal or family history of asthma \\
\hline & Gastroesophageal reflux & Feeding refusal, respiratory symptoms \\
\hline & Foreign body aspiration & Sudden onset of choking or vomiting with choking \\
\hline & Pneumonia & $\begin{array}{l}\text { Fever, rales, and rhonchi with decreased breath sounds, } \\
\text { absent or only infrequent wheezing }\end{array}$ \\
\hline & Anaphylaxis & Allergic history, exposures \\
\hline & $\begin{array}{l}\text { Vascular rings or slings impinging the } \\
\text { airway }\end{array}$ & $\begin{array}{l}\text { Lack of accompanying symptoms of respiratory infection, } \\
\text { chronicity }\end{array}$ \\
\hline
\end{tabular}




\subsection{Croup}

When viral infections spread distally beyond the larynx to involve the trachea and the bronchi, the infection is referred to as laryngotracheitis or laryngotracheobronchitis (LTB). LTB is a more descriptive term, but "croup" is more commonly used.

Viral croup is the most common infectious cause of upper airway obstruction in young children. Infection involves the respiratory mucosa along the subglottic region. Anatomically, the subglottic diameter and circumference correlate with the age and size of the child. The smaller diameters make very young children prone to the obstructive process caused by infection-associated edema. The incidence of croup is highest among children between 3 months and 3 years of age. Outbreaks of croup typically occur in the fall and early winter just preceding the onset of RSV and influenza disease (• Fig. 7.2). Parainfluenza viruses types 1, 2, and 3 account for nearly $80 \%$ of all cases (• Fig. 7.3). Influenza A and B viruses can cause severe LTB and are more commonly associated with the development of secondary bacterial tracheitis and pneumonia caused by Staphylococcus aureus, Streptococcus pneumoniae, Haemophilus influenzae, and Moraxella catarrhalis [1]. Respiratory syncytial virus (RSV) and other common respiratory viruses, such as adenoviruses, rhinoviruses, human metapneumoviruses, human bocaviruses, and human coronaviruses (NL63 in particular), are less common causes of acute viral croup.

A child with croup typically presents with a prodrome of nonspecific upper respiratory symptoms preceding the onset of laryngeal symptoms for approximately $24 \mathrm{~h}$. Symptoms of coryza and hoarseness are generally present early on.
Progression of illness involves development of a characteristic cough that has a barking quality, like a seal. Varying degrees of inspiratory stridor become apparent, sometimes associated with tachypnea. These symptoms generally start abruptly and are typically worse at night (see $>$ Box 7.2). Most children with croup have low-grade fever (generally $\leq 101{ }^{\circ} \mathrm{F}$ ) and do not appear toxic, but some of the viral causes, particularly parainfluenza virus type 3 , have the potential to cause higher fever. The progression of disease is variable among children. Most gradually recover over the course of 3-7 days. Severe disease requiring endotracheal intubation is unusual, occurring in fewer than $2 \%$ of cases. Using assessment tools such as a croup score [2] may be helpful in determining the severity of the disease and to guide management in acute care settings ( $\triangleright$ Box 7.3).

Since the diagnosis of croup is generally made on clinical grounds, the routine use of airway or chest radiography is not indicated. If radiographs are obtained, a classic "steeple sign" may be apparent on the anterior-posterior view of the neck. The finding is due to the abnormally long area of airway narrowing that extends well below the anatomic narrowing normally seen at the level of the larynx.

At home management of croup has traditionally included the use of mist or humidified air. Despite its widespread use, no clinical benefit was noted from studies of children seen in acute care settings. In contrast, a recent Cochrane review [3] concluded that a single dose of corticosteroids should be used to treat most children with croup. Corticosteroid treatment is associated with a shorter duration of stay in the emergency department or in the hospital, if admitted, fewer hospitalizations, and fewer return visits to emergency departments. Most experts cur-
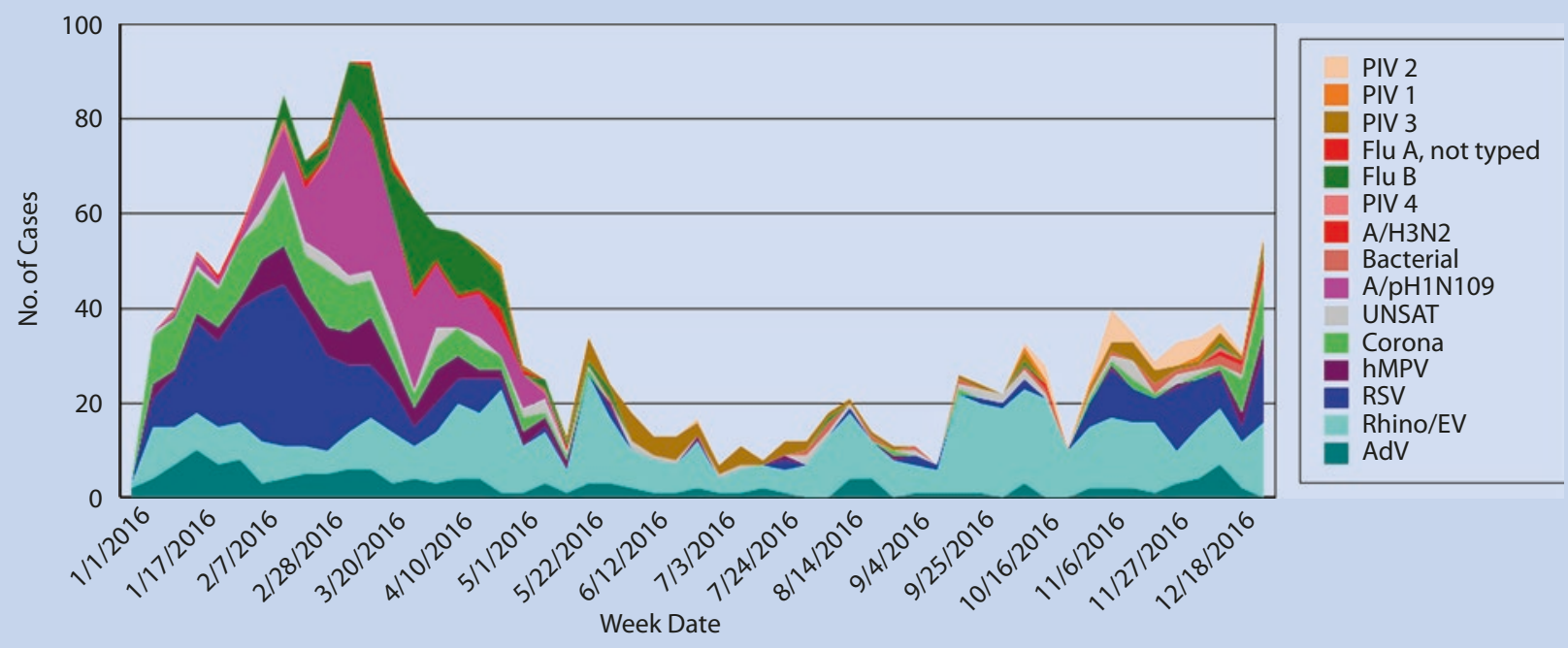

- Fig. 7.2 Respiratory viruses identified by PCR technology from patient samples submitted to Albany Medical Center's Molecular Diagnostics Laboratory during 2016. Late fall and winter seasonal patterns are seen for respiratory syncytial virus (RSV, dark blue), coronaviruses (bright green), and human metapneumovirus (hMPV, maroon). The detection of parainfluenza viruses (PIV 1, 2, and 3, tan, orange, and light brown, respectively) was also seasonal, starting earlier in the fall. The detection of adenoviruses ( $\mathrm{AdV}$, dark green) and rhinoviruses/enteroviruses (rhino/EV, light blue) occurred throughout the year, without clear seasonal patterns. (Figure courtesy of Albany Medical Center Virology/Molecular Diagnostics Laboratory) 
- Fig. 7.3 This pie chart shows the percentage of pediatric croup cases caused by specific respiratory viruses

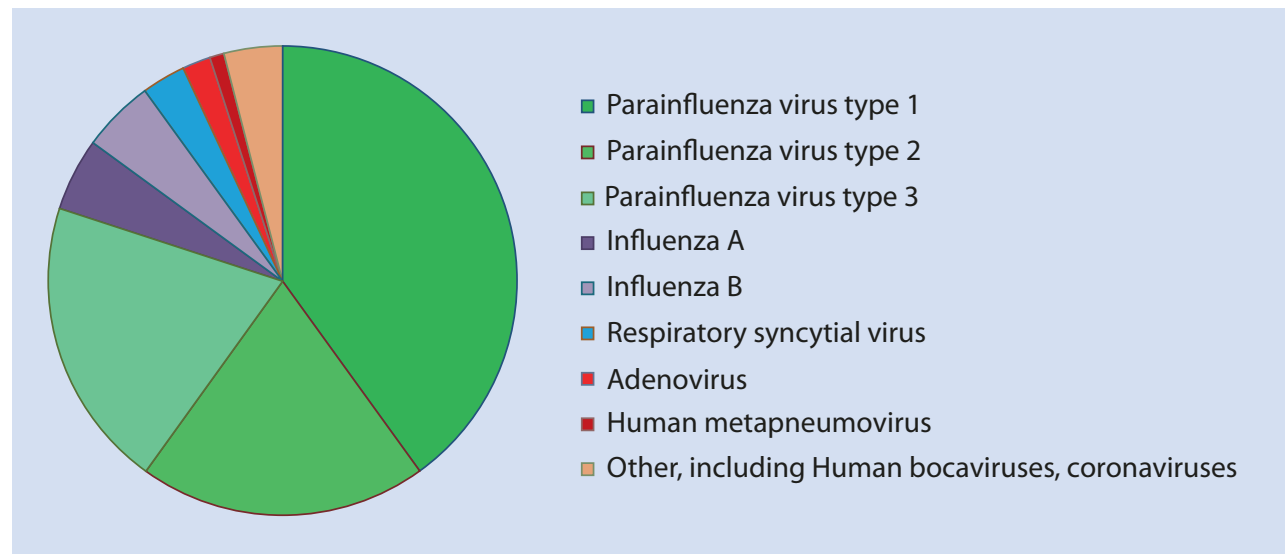

Box 7.2 Clinical Features of Croup

- Most common in children between 3 months and 3 years of age

- Pathology located in the subglottic region

- Gradual onset with an upper respiratory prodrome

- Low-grade or absence of fever

- Nontoxic appearance

- Varying degrees of stridor from mild to severe

- Barky cough that sounds like a seal

- Cough and stridor often worse at night

\section{Box 7.3 Clinical Features Used to Assess Croup Severity}

\begin{tabular}{|c|c|}
\hline Clinical feature & Score \\
\hline Level of consciousness & $\begin{array}{l}\text { Normal, including sleep }=0 \\
\text { Disoriented }=5\end{array}$ \\
\hline Cyanosis & $\begin{array}{l}\text { None }=0 \\
\text { With agitation }=4 \\
\text { At rest }=5\end{array}$ \\
\hline Stridor & $\begin{array}{l}\text { None }=0 \\
\text { With agitation }=1 \\
\text { At rest }=2\end{array}$ \\
\hline Air entry & $\begin{array}{l}\text { Normal }=0 \\
\text { Decreased }=1 \\
\text { Markedly decreased }=2\end{array}$ \\
\hline Retractions & $\begin{array}{l}\text { None }=0 \\
\text { Mild }=1 \\
\text { Moderate = } 2 \\
\text { Severe }=3\end{array}$ \\
\hline
\end{tabular}

A total score of 2 or less indicates mild croup, between 3 and 7 indicates moderate croup, between 8 and 11 indicates severe croup, and 12 or higher indicates impending respiratory failure (Ref. [2])

rently recommend the use of dexamethasone which can be administered orally, intravenously, or intramuscularly. Nebulized budesonide has also been used. Nebulized racemic epinephrine is also effective at achieving temporary symptomatic improvement in children with moderate to severe croup [4]. While the treatment is safe, there may be transient side adverse effects such as pallor and tachycardia. Many institutions have developed their own algorithms for the management of pediatric croup in the acute outpatient setting. One excellent algorithm for the assessment and management of croup can be found at www. topalbertadoctors.org/download/252/croup_guideline.pdf (Appendix A, accessed June 27, 2017).

For children with moderate croup who fail to improve within 4-6 h after the administration of a corticosteroid, hospitalization should be considered. Children with severe croup should receive a single dose of corticosteroid and a dose of nebulized racemic epinephrine. Repeat doses of nebulized racemic epinephrine are then administered as needed in an effort to avoid the need for endotracheal intubation. Intensive care support may be needed if there is an insufficient response to repeated doses. It is important to remember that the beneficial effects of nebulized racemic epinephrine wane over $1-2 \mathrm{~h}$. Close observation is necessary as the epinephrine effect declines.

Children with croup who consistently have oxygen saturations below $92 \%$ in room air should receive supplemental oxygen. Other available treatment modalities such as the use of nebulized saline, inhaled helium and oxygen mixture (heliox), and antitussive or decongestant medications are not generally recommended. Antibiotics are also not indicated unless there is a suspicion for a secondary bacterial infection. Croup, caused by influenza A or B, can be treated with oseltamivir.

The vast majority of children experiencing croup do not have complications, but a small percentage require endotracheal intubation and mechanical ventilation. Children with uncomplicated croup generally improve within 2-3 days.

The differential diagnosis for croup includes airway trauma (especially secondary to caustic agents that are swallowed or inhaled), angioedema, foreign body aspiration, tracheitis, epiglottitis, and gastroesophageal reflux ( Box 7.1). Retropharyngeal, parapharyngeal, tonsillar, or peritonsillar abscesses may present with stridor due to acute swelling. Such patients typically have high fever and appear very ill or toxic. Pharyngeal diphtheria could mimic 
some of the features of croup and should be considered in the differential diagnosis if the patient is unimmunized or has been exposed.

\subsection{Bacterial Tracheitis}

Bacterial tracheitis is an invasive, exudative bacterial infection of the soft tissues of the trachea and adjacent structures. It may be difficult to differentiate clinically from viral croup, but children with bacterial tracheitis typically appear toxic, have high fevers, and are in significant respiratory distress. When bacterial tracheitis is seen, it is almost always in the setting of prior airway damage such as occurs with prolonged intubation or during an acute viral infection [1].

Organisms that cause bacterial tracheitis are generally those bacterial species that inhabit the normal upper respiratory tract, collectively referred to as oropharyngeal flora. Staphylococcus aureus, Streptococcus pyogenes, and Streptococcus pneumoniae are the most common causes, but Gram-negative enteric bacteria such as Escherichia coli, Klebsiella pneumoniae, and Pseudomonas aeruginosa can also cause infection of the trachea, especially in hospitalized patients. Influenza $\mathrm{A}$ is one of the most common predisposing viral infections, but other respiratory viruses including RSV, parainfluenza viruses, and measles have also been implicated.

Clinical features of acute bacterial tracheitis share many features with the more common viral infections in this anatomic area. Presenting symptoms may include stridor, cough, and varying degrees of respiratory distress. The infection may progress rapidly causing airway obstruction or impending respiratory failure. Signs that are concerning for impending respiratory failure include marked retractions, evidence of fatigue, listlessness, or depressed level of consciousness. In contrast to most children with viral croup, fever is almost invariably present and is generally high grade $\left(39^{\circ} \mathrm{C}\right.$ or greater). Patients appear toxic. The severity of the clinical presentation, or acute worsening of symptoms in any patient recovering from viral croup, strongly suggests that an underlying secondary bacterial infection has intervened. Clinical features of the antecedent viral infection such as rhinorrhea, cough, and even wheezing may still be present.

Management of bacterial tracheitis requires provision of a stable airway and the administration of broad-spectrum, empiric antibiotics directed at the group of oropharyngeal pathogens known to be the usual causative agents. Most patients require endotracheal intubation. During the procedure, samples should be collected for Gram stain and bacterial culture. Microbiologic results should be used to de-escalate the initial antibiotic regimen, if appropriate.

The differential diagnoses for acute bacterial tracheitis and acute viral laryngotracheobronchitis are similar and include foreign body aspiration, pharyngeal diphtheria, epiglottitis, and peritonsillar, parapharyngeal, and retropharyngeal abscesses ( $\triangleright$ Box 7.1). Final diagnosis may require direct visualization of the airway, a procedure best performed under highly controlled circumstances, by individuals experienced in quickly and effi- ciently establishing a secure airway under difficult circumstances, including the use of cricothyrotomy, if necessary.

\subsection{Epiglottitis}

Epiglottitis is a bacterial infection of the epiglottis and supraglottic structures that result in marked swelling of the epiglottis associated with a high risk for acute, complete, airway obstruction (• Fig. 7.4). Historically, epiglottitis was almost always caused by $H$. influenzae, serotype B. In the United States, infants and young children have been immunized against $H$. influenzae, serotype B, since 1990 . Prior to vaccine introduction, approximately 20,000 cases of invasive disease were reported annually among children less than 5 years of age. Presently, fewer than 50 annual cases occur, almost exclusively among children who are too young to have completed the primary vaccine series, unvaccinated by parental choice, or found to have a primary humoral immune deficiency. Several other bacterial pathogens can cause acute epiglottitis but none with the proclivity once seen with $H$. influenzae serotype B. Examples of pathogens known to cause sporadic cases of epiglottitis include $H$. influenzae serotypes A and F and non-typeable strains, Streptococcus pyogenes (group A streptococcus) and Staphylococcus aureus.

Children with epiglottitis present with a sudden onset of high fever and acute respiratory distress. They are pale and anxious and appear toxic. They prefer to sit in a tripod position, leaning forward with their hands on their knees, their head in a "sniffing position," and their face in a raised position in an instinctual attempt to optimize the patency of their narrowing airway. They can develop sudden and complete airway obstruction, so they should be perturbed as little as possible. The clinical scenario is not a time to insist on performing an examination of the oropharynx, performing

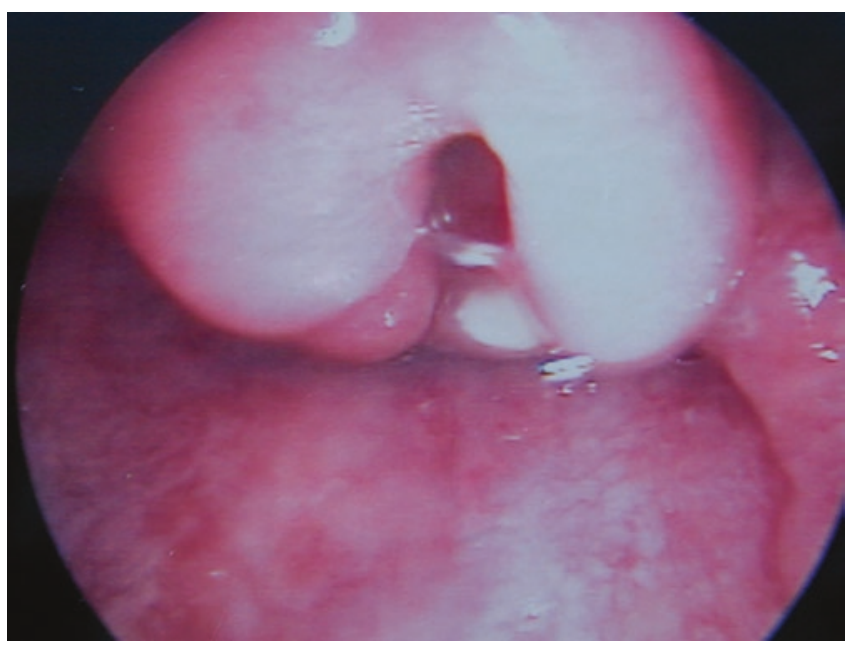

- Fig. 7.4 Laryngoscopic view of the inflamed and markedly swollen epiglottis of a 3-year-old child with epiglottitis. Bacterial cultures that were collected by swabbing the surface of the epiglottis immediately after the airway was secured grew Haemophilus influenzae, serotype B. A review of the medical history confirmed that the boy had not been immunized. (Photo courtesy of Jason Mouzakes, MD) 
phlebotomy, or inserting an intravenous catheter. The child should be left undisturbed in the position of greatest comfort to them, while personnel skilled in emergency airway management assemble to prepare to secure the airway under highly controlled condition, such as the operating room. Supplemental oxygen should be offered if the child does not become agitated with its delivery. The airway must be secured as the first priority. Antibiotics are indicated and should include a second- (e.g., cefuroxime) or third- (e.g., ceftriaxone) generation cephalosporin to provide coverage for $H$. influenzae, serotype B. If the microbiology laboratory reports growth of a beta-lactamase-negative $H$. influenzae, serotype B isolate, ampicillin may be used to complete the antibiotic course. First-generation cephalosporins should not be used as they have no activity against $H$. influenzae.

Children with epiglottitis undergo endotracheal intubation for acute airway management by an experienced operator and should remain intubated until there is an air leak present around the endotracheal tube. While intubated, care must be taken to avoid accidental dislodgement of the endotracheal tube, including the use of adequate sedation, and gentle, appropriate arm and hand restraints. With antibiotic treatment, the epiglottic swelling associated with the infection gradually subsides over 3-5 days. Most children recover without any adverse effects.

\section{Case Study}

Practical Examples

A frantic mother calls the on-call physician during the night. Her 3-year-old child had a runny nose and cough yesterday but woke up a few minutes ago from coughing so hard and is now making a scary sound when he is trying to breathe in, like he cannot get any air. You ask several questions to assess the severity of his illness, which you suspect to be croup. She says he is awake and is not "blue," but he is making a whistling sound when he breathes in. His chest is "sucking inward." Based on these features, you conclude that he probably has moderate croup and would benefit from an evaluation in the local emergency department (ED). On arrival to the local $E D$, the boy's respiratory rate is 40 breaths per minute, and his oxygen saturation in room air is $94 \%$. He has inspiratory stridor that worsens when he becomes agitated during the physical examination. He has some intercostal and supraclavicular retractions.
A dose of dexamethasone is administered followed by a respiratory treatment with aerosolized racemic epinephrine. After the respiratory treatment is done, his symptoms are improved. His respiratory rate is now normal at 25 breaths per minute, and his oxygen saturation in room air is $98 \%$. His retractions are improved, and stridor is absent. After $4 \mathrm{~h}$ of observation, his symptoms did not recur, so he is discharged home with specific guidance on reasons to return to the ED.

\subsection{Exercises}

Please refer to the supplementary information section for answers to these exercises.

Match the clinical feature with the most appropriate diagnosis. Each diagnosis is only used once.

\begin{tabular}{|l|l|}
\hline Pathogen & $\begin{array}{l}\text { Characteristic } \\
\text { finding }\end{array}$ \\
\hline $\begin{array}{l}\text { 1. Stridor } \\
\text { 2. Hoarse voice }\end{array}$ & A. Epiglottitis \\
\hline $\begin{array}{l}\text { 3. Toxic appearance with high fever } \\
\text { 4. Unimmunized child with } \\
\text { respiratory distress }\end{array}$ & B. Laryngitis \\
\hline $\begin{array}{l}\text { 5. Wheezing } \\
\text { C. Croup }\end{array}$ \\
\hline
\end{tabular}

? The optimal management of a child with moderate croup includes which of the following:
A. Mist therapy, fluids, $\mathrm{O} 2$, and dexamethasone
B. Fluids, $\mathrm{O} 2$, and dexamethasone
C. O2, dexamethasone, and antibiotics
D. Antibiotics, racemic epinephrine, and $\mathrm{O} 2$
E. Racemic epinephrine, $\mathrm{O} 2$, and mist

\subsection{Summary}

Childhood illnesses of the middle airway are very common and are caused by acute viral infections. Laryngitis is often associated with upper respiratory tract infection and can be one of the findings in patients who also have croup (LTB). Viral croup is the most common cause of acute respiratory obstruction in infants and young children leading to a substantial number of ED visits during the fall and winter seasons. Proper management includes the administration of a single dose of corticosteroids and, if necessary for more severe cases, aerosolized racemic epinephrine. Most children recover without sequelae. Acute bacterial tracheitis is rare but typically follows a primary problem that led to mechanical injury (endotracheal intubation) or friability (any acute respiratory viral infection) of the respiratory mucosa. Epiglottitis is rare in the era of vaccination against $H$. influenzae serotype B disease but should be considered in a toxic-appearing, unimmunized child with a high fever and respiratory distress.

\subsection{Bronchiolitis}

Bronchiolitis is a lower respiratory tract infection that primarily affects children under 2 years of age. It is one of the most common causes of illness and the most common reason for hospitalization in infants and young children. Most of the infants who require hospitalization have identifiable risk factors that place them at high risk for bronchiolitis, but even otherwise healthy infants and older children can develop severe infection requiring hospitalization. Some develop respiratory failure requiring mechanical ventilation. Global estimates indicate that more than 3.4 million infants require hospitalization and as many as 250,000 infants die from bronchiolitis annually. Ninety-nine percent 
- Fig. 7.5 This pie chart shows the percentage of pediatric bronchiolitis cases caused by specific respiratory viruses

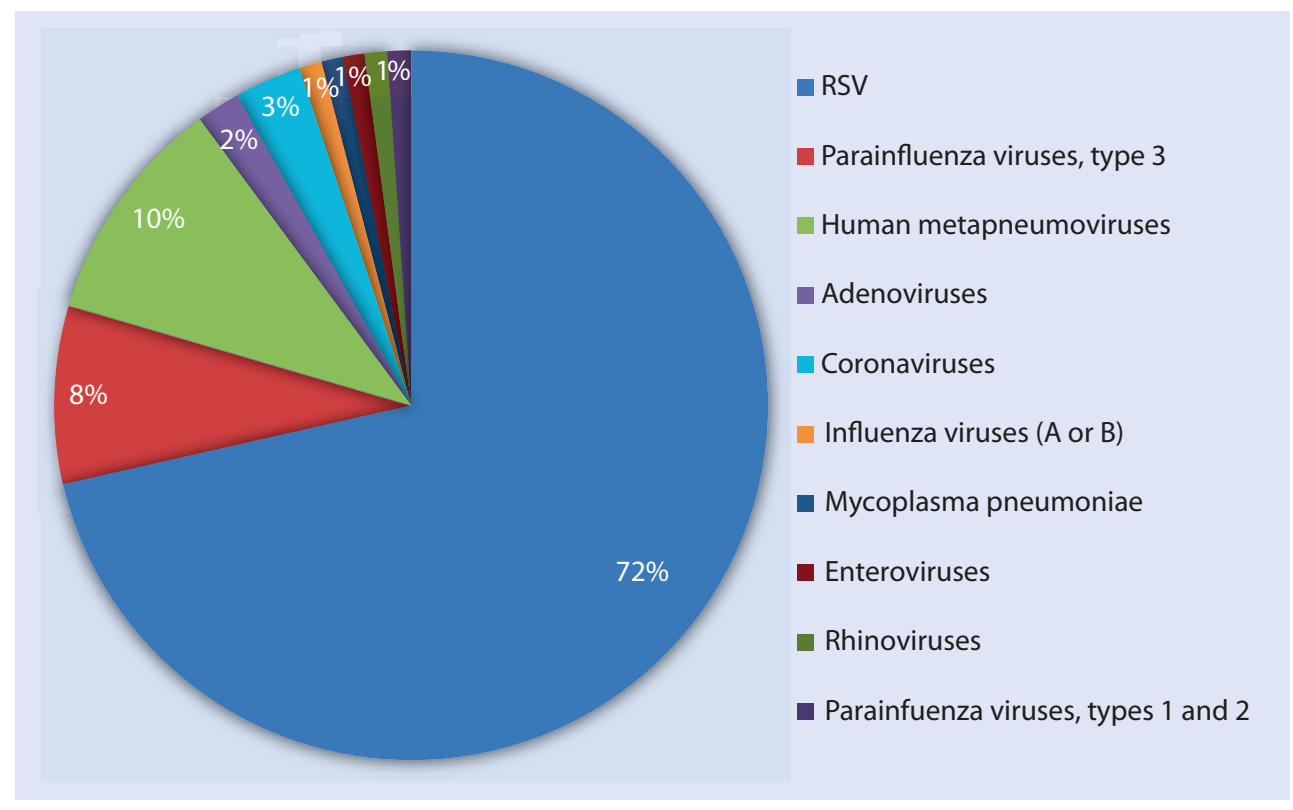

of all infant deaths from bronchiolitis occur in underdeveloped countries.

\subsection{Definitions}

Bronchiolitis: Bronchiolitis is a viral infection of the terminal bronchioles, generally preceded by infection in the upper and middle respiratory tract. The illness is characterized by wheezing, tachypnea, and respiratory distress that ranges in severity from "the happy wheezer" to respiratory failure. The term "viral bronchiolitis" is a diagnosis generally restricted to infants and very young children who present clinically with wheezing and tachypnea typically associated with other common signs of an acute viral infection of the respiratory tract including cough, nasal congestion, and rhinorrhea.Bronchiolitis is one of the most common respiratory illnesses in children worldwide [5]. Outbreaks of bronchiolitis occur annually, and while the precise timing and overall severity of each year's outbreak vary from year to year, region to region, general seasonal patterns are quite predictable in much of the world. In temperate climates, outbreaks occur during the fall and winter months as respiratory viruses circulate throughout communities. In tropical and subtropical climates, the yearround baseline of disease activity tends to be higher than seen in temperate areas, with outbreaks of disease occurring during the rainy season. Limited data suggest that desert climates are associated with substantial bronchiolitis disease activity yearround.

Bronchiolitis affects infants and young children, with a peak incidence occurring between 2 and 6 months of age. Respiratory syncytial virus (RSV) is, by far, the leading common cause of bronchiolitis, accounting for two thirds of cases. The second and third most common causes, human metapneumovirus and parainfluenza virus type 3, account for more than half of the remaining cases. All of the other common respiratory viruses have potential to cause bronchiolitis as part of their potential spectra of disease, but each contributes to only a small percentage of total cases (• Fig. 7.5) [6]. Bronchiolitis develops when a viral upper respiratory tract infection progresses to the distal lower respiratory tract. The early signs and symptoms of cough, congestion, and rhinorrhea, with or without fever, persist as the infant or child begins to wheeze and exhibit varying degrees of respiratory distress. The onset of wheezing and tachypnea heralds the development of lower respiratory tract involvement. Young children are particularly prone to bronchiolitis with wheezing because smaller airways are more prone to partial or complete obstruction when they become inflamed and filled with mucous. Shifting areas of local obstruction and mucous plugging results in air trapping that can usually be appreciated on chest radiography as hyperinflation and atelectasis (- Fig. 7.6) and is, at least in part, responsible for the diffuse wheezing heard on chest auscultation. Tachypnea, with respiratory rates of 100 breaths per minute or more, is not uncommon and will eventually impede the infant's ability to adequately feed. Oxygen saturation, as measured by pulse oximetry, can vary minute to minute due to shifting areas of mucous plugging and atelectasis that lead to varying degrees of ventilation to perfusion mismatch [7]. On clinical grounds, viral bronchiolitis and viral pneumonia are difficult to distinguish from one another since they represent a spectrum of lower respiratory tract illness that exist on a continuum. Accurately distinguishing between the two is not clinically important since the approach to patient management is the same.

The pathophysiology of bronchiolitis originates from infection of the cells lining the terminal bronchioles. The infection causes direct cellular damage while also stimulating local host inflammatory responses. Virus-induced inflammation results in edema, mucus production, and the recruitment of inflammatory cells. Sloughing of dead epithelial cells into the inflamed, mucous-filled airway lumen leads to obstruction of the small airways.Most infants who develop bronchi- 


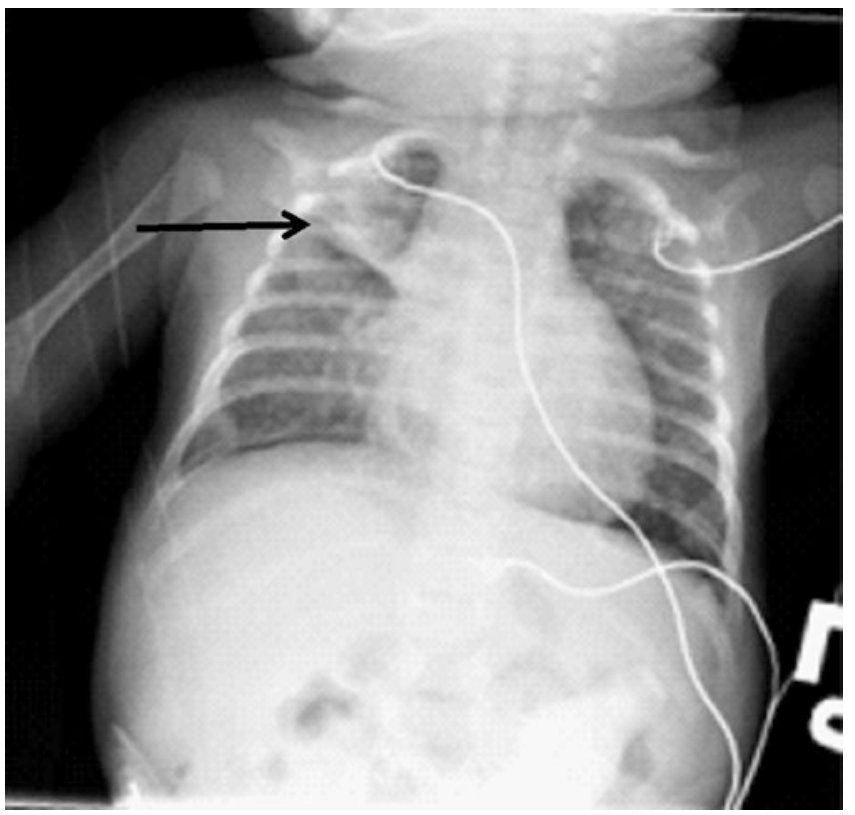

- Fig. 7.6 This chest radiograph, from a young infant with RSV bronchiolitis, demonstrates the typical radiographic features of bronchiolitis including hyperinflation, flattening of the diaphragms, and areas of atelectasis, visible here as a linear density in the right upper lung (arrow)

olitis will not require hospitalization. Risk factors known to be associated with more severe disease and therefore more likely to require hospitalization are well described $(\bullet$ Box 7.4) [8]. Prematurity, low birthweight, chronic lung disease, hemodynamically significant congenital heart disease, and age less than 3 months are independent risk factors for severe disease, especially when bronchiolitis is caused by RSV. Children with exposure to cigarette smoke or other air pollutants, who live in crowded households and at high altitude, attend daycare, and have preschool-aged siblings, are also at risk for more severe disease. The ability of an infant to breast- or bottle-feed is a good indication of the clinical severity of their illness and should be observed if possible. Those who cough, struggle to breathe, or sputter during feeding should be considered for hospitalization. Infants with tachypnea above 60 breaths per minute and/ or oxygen saturations less than $92 \%$ should also be considered for admission. Treatment of children who are hospitalized with bronchiolitis is supportive $[9,10]$ ( $\triangleright$ Box 7.5). Supplemental oxygen should be provided to those infants who have oxygen saturations of less than $92 \%$ in room air. Oxygen saturation, as measured by pulse oximetry, can vary from minute to minute and should be measured continuously in hospitalized infants. Intravenous fluids should be administered to those infants who are unable to feed due to respiratory distress. Infants with severe hypoxemia or clinical evidence of fatigue from ongoing tachypnea should be considered for endotracheal intubation and mechanical ventilation.Prevention of bronchiolitis is challenging. The only etiologies of bronchiolitis for which vaccines are available are the influenza viruses. While the burden of influenza virus-associated disease is substantial, it accounts for only a
Box 7.4 Risk Factors for the Development of Severe Bronchiolitis

\begin{tabular}{|c|c|c|}
\hline Patient factors & $\begin{array}{l}\text { Environmental } \\
\text { factors }\end{array}$ & Social factors \\
\hline Prematurity & $\begin{array}{l}\text { Exposure to } \\
\text { tobacco smoke }\end{array}$ & $\begin{array}{l}\text { Older } \\
\text { siblings }\end{array}$ \\
\hline Low birthweight & $\begin{array}{l}\text { Exposure to } \\
\text { other air } \\
\text { pollutants }\end{array}$ & $\begin{array}{l}\text { Daycare } \\
\text { attendance }\end{array}$ \\
\hline $\begin{array}{l}\text { Chronic lung disease, } \\
\text { particularly } \\
\text { bronchopulmonary } \\
\text { dysplasia; abnormal } \\
\text { airway anatomy }\end{array}$ & $\begin{array}{l}\text { Living at an } \\
\text { altitude higher } \\
\text { than } 2500 \mathrm{~m} \\
(\sim 8200 \mathrm{ft})^{\mathrm{a}}\end{array}$ & $\begin{array}{l}\text { Twins and } \\
\text { other } \\
\text { multiple } \\
\text { births }\end{array}$ \\
\hline $\begin{array}{l}\text { Hemodynamically } \\
\text { significant congenital } \\
\text { heart disease, } \\
\text { especially if } \\
\text { associated with } \\
\text { left-to-right shunting }\end{array}$ & $\begin{array}{l}\text { Crowded } \\
\text { household }\end{array}$ & \\
\hline \multicolumn{3}{|l|}{$\begin{array}{l}\text { Age less than } \\
3 \text { months }\end{array}$} \\
\hline \multicolumn{3}{|l|}{ Immunodeficiency } \\
\hline \multicolumn{3}{|l|}{ Down syndrome } \\
\hline Neurologic disease & & \\
\hline Native American & & \\
\hline
\end{tabular}

aExamples: Asia, Lhasa, Tibet; North America, Leadville, CO, USA; South America, Quito, Ecuador; Africa, Adi Keyh, Eritrea. The highest inhabited towns on the other three continents are below 8200 feet. Europe, Ushguli, Georgia, at 6900 feet; Australia, Perisher Village, at 5600 feet; and Antarctica, both small settlements sitting close to sea level

Box 7.5 Treatment and Management of Acute Viral Bronchiolitis

- Most can be managed at home with supportive care

- Hospitalize those who are unable to feed and those who are hypoxemic in room air

- Administer supplemental oxygen if needed

- Replace fluid deficits; maintain hydration

- Attempt to keep nasal passages clear, because young infants are obligate nose breathers

- Bronchodilator therapy

- No convincing evidence to support routine use

- A trial of aerosolized bronchodilator can be considered. If used, assess response

- If no improvement in oxygen saturation or respiratory distress, discontinue use

- If undesirable side effects are seen, such as excessive tachycardia or pallor, discontinue use

- Glucocorticoid therapy

- No convincing evidence to support routine use

- Antimicrobial therapy

- Oseltamivir can be considered for influenza virus-associated bronchiolitis

- Secondary bacterial infections are uncommon, but when suspected antibiotics should be administered 
very small percentage of bronchiolitis cases (• Fig. 7.5) [8, $10,11]$. RSV bronchiolitis currently can be moderated or prevented by the provision of a monoclonal antibody, palivizumab, if administered monthly during the RSV season by IM injection. Its use, however, is restricted to very highrisk infants and does not address the greater problem of the enormous disease burden carried by otherwise healthy infants during their first 3 months of life. The prognosis of bronchiolitis is excellent. Most children recover completely within 5-7 days. Long-term studies of infants with wheezing due to bronchiolitis have shown that a substantial percentage will go on to have further episodes of reactive airway disease through early adolescence $[6,11]$. A link between moderate to severe viral bronchiolitis in infancy and the development of chronic reactive airway disease, including asthma, is supported by longitudinal studies, but it remains unclear if the association is causal.The differential diagnosis of bronchiolitis includes acute exacerbation of asthma, gastroesophageal reflux, aspiration pneumonia, foreign body aspiration into the lower airway, vascular rings or slings, and, uncommonly, an acute anaphylactic reaction $(\triangleright$ Box 7.1).

Case Study

Practical Examples

A 4-month-old previously healthy male infant born at term presents to the emergency department with respiratory distress. His parents state that he had a cold starting 2 days ago with runny nose, cough, and occasional low-grade fever. His 3-year-old sister had the same thing about a week ago, but she has recovered. They note that this morning he seemed to be breathing fast and his chest was "sucking in." He was unable to drink his bottle and had a spasm of coughing during an attempt to feed. His parents spoke with their primary care provider, and she advised an emergency department visit. The infant has received all recommended immunizations for his age. The family history is negative for reactive airway disease and other pulmonary conditions.

On physical examination, the infant appears pale. His vitals include a rectal temperature of $38^{\circ} \mathrm{C}$, a heart rate of 160 beats per minute, and a respiratory rate of 60 breaths per minute. His blood oxygen saturation is $91 \%$ in room air. $\mathrm{He}$ has copious nasal secretions and classic signs and symptoms of respiratory distress for his age including tachypnea, nasal flaring, intercostal retractions, and prominent inspiratory and expiratory wheezing in all lung fields. The remainder of his physical examination is unremarkable.

You suspect which of the following diagnoses?
A. Laryngotracheobronchitis (croup)
B. Epiglottitis
C. Pneumonia
D. Bronchiolitis
E. Reactive airway disease
What is most common organism that causes the above condition in young infants?
A. Respiratory syncytial virus
B. Parainfluenza virus, type 3
C. Haemophilus influenzae
D. Streptococcus pneumoniae
E. There is no infectious cause of this condition

In addition to providing supplemental oxygen, which of the following options describes the most appropriate management for this child?

A. Administer fluids, obtain a chest radiograph, and start treatment with antibiotics

B. Administer fluids and start treatment with dexamethasone

C. Administer fluids and start treatment with racemic epinephrine

D. Administer fluids and consider a trial dose of albuterol

E. Arrange for emergency endotracheal intubation

\subsection{Summary}

Bronchiolitis is an acute viral infection of the terminal bronchioles. It manifests as respiratory distress and wheezing in young children. It is the most common cause of respiratory distress requiring hospitalization in children under 5 years of age. Many respiratory viruses can cause bronchiolitis, but the most common to do so is RSV. Management consists mainly of providing symptomatic support including oxygen therapy and fluids as needed to maintain hydration. Pre-exposure passive antibody prophylaxis, palivizumab, is available to help prevent serious RSV infection in the highest-risk infants. Active vaccination against influenza is available starting at 6 months of age. Influenza viruses are the only causes of bronchiolitis for which antiviral medication is available.

\section{References}

1. Cherry JD. Croup (laryngitis, laryngotracheitis, spasmodic croup, laryngotracheobronchitis, bacterial tracheitis, and laryngotracheobronchopneumonitis) and epiglottitis (supraglottitis). In: Cherry JD, Harrison GJ, Kaplan SL, editors. Feigen and Cherry's textbook of pediatric infectious diseases, vol. 1. 7th ed. Philadelphia: Saunders; 2014. p. 241-65.

2. Westley CR, Cotton EK, Brooks JG. Nebulized epinephrine by IPPB for the treatment of croup: a double blinded study. Am J Dis Child. 1978;132:484.

3. Russell KF, Liang Y, O'Gorman K, Johnson DW, Klassen TP. Glucocorticoids for croup. Cochrane Database Syst Rev. 2011:CD001955.

4. Bjornson C, Russell K, Vandermeer B, Klassen TP, Johnson DW. Nebulized epinephrine for croup in children. Cochrane Database Syst Rev. 2013;(10):CD006619.

5. Nair H, Nokes DJ, Gessner BD, Dherani M, Madhi SA, Singleton RJ, et al. Global burden of acute lower respiratory infections due to 
respiratory syncytial virus in young children: a systematic review and meta-analysis. Lancet. 2010;375(9725):1545-55.

6. Florin TA, Plint AC, Zorc JJ. Viral bronchiolitis. Lancet. 2017;389: 211-4.

7. Meissner HC. Bronchiolitis. In: Long SS, Pickering LK, Prober CG, editors. Principles and practice of pediatric infectious disease. 4th ed. New York: Elsiever; 2012. p. 162-71.

8. Shi T, Balsells E, Wastnedge E, Singleton R, Rasmussen ZA, Zar HJ, et al. Risk factors for respiratory syncytial virus associated with acute lower respiratory infection in children under five years: systematic review and meta-analysis. J Glob Health. 2015;5(2):020416.

9. House SA, Ralston SL. Diagnosis, prevention, and management of bronchiolitis in children: review of current. Minerva Pediatr. 2017;69(2):141-55.
10. Ralston SL, Lieberthal AS, Meissner HC. Clinical practice guideline: the diagnosis, management, and prevention of bronchiolitis. Pediatrics. 2015;136(4):728.

11. Welliver RC. Bronchiolitis and infectious asthma. In: Feigen RD, Cherry JD, Demmler GJ, Kaplan SL, editors. Textbook of pediatric infectious diseases, vol. 1. 5th ed. Philadelphia: Saunders; 2005. p. 273-85.

Related Links to Journals, Books, and/or URLs

Alberta Clinical Practice Guidelines Guideline Working Group. Guidelines for the diagnosis and management of croup. www. topalbertadoctors.org/download/252/croup_guideline.pdf.

http://pediatrics.aappublications.org/content/pediatrics/early/2014/10/21/ peds.2014-2742.full.pdf. 